\title{
Varietal Variations in Rice Seedling Growth under Low Oxidation-Reduction Potentials
}

\author{
Keiji Iimura, Toshinori Abe and Takeo Sasahara* \\ Laboratory of Plant Breeding, Faculty of Agriculture, Yamagata University, 1-23 Wakaba, Tsuruoka, Yamagata 997-8555, Japan
}

In direct seeding of rice (Oryza sativa $\mathbf{L}$.), rice seedlings are exposed to low oxidation-reduction (redox) potential soil, and to low temperatures in cold areas. In order to trace the genealogy of tolerance to low redox potential among Japanese rice cultivars, we selected 12 Japanese rice cultivars that had been released over the past century and determined the ability of their seedlings to tolerate immersion in low redox culture solution of $\mathbf{E h}=$ -150 to $-180 \mathrm{mv}$. Seedlings with coleoptiles and radicles of about 1 to $2 \mathrm{~cm}$ were incubated in low redox potential culture solution for 2 days at 18 and $30^{\circ} \mathrm{C}$, and then in distilled water for 3 days at the same temperatures to examine the recovery abilities. The lengths of shoots and roots were measured after pre-germination, after low redox treatment, and after recovery from damage that occurred in the de-oxidized solution. At $30^{\circ} \mathrm{C}$, the tolerance of low redox potentials was positively and significantly correlated with recovery from damage that occurred in the de-oxidized solution. The high tolerance of recent cultivars to these low redox potentials at $30^{\circ} \mathrm{C}$ appeared to originate from Fujisaka 5. However, at $18^{\circ} \mathrm{C}$, the differences among the cultivars in their tolerance of low redox potentials and in their ability to recovery became small.

Key Words: Oryza sativa, direct sowing, oxidationreduction, redox potential, soil reduction.

\section{Introduction}

Rice (Oryza sativa L.) is a crop that is cultivated under flooded conditions. Either rice plants or rice seedlings can be planted in flooded soil. The latter method, referred to as direct seeding, is more labor saving and less expensive than transplanting (Fujioka 1987), but it inevitably exposes the seedlings to hypoxic conditions. Mature rice plants are endowed with a well-developed air-ventilation system (Arikado 1955), which reaches from the stomata in leaves via the leaf sheath and culm to the roots. By contrast, rice seedlings do not have a well-developed air-ventilation system (Kawai and Uchimiya 1999). Thus, rice seedlings must acquire ener-

Communicated by K. Yamamoto

Received March 4, 2002. Accepted June 11, 2002.

*Corresponding author (e-mail: CYN00524@nifty.ne.jp) gy (ATP, etc.) and/or various cellular components needed for seedling growth, such as glucose and amino acids, mainly through anaerobic metabolism (Kanda and Takahashi 1951, Takahashi 1955).

As early as the 1930's, it was found that rice roots require more oxygen for full growth than the roots of other aquatic plants (Miura 1933), even though rice plants are endowed with an air-ventilation system which runs from the leaves to the roots via sheaths called lysigenous aerenchyma. Therefore, in flooded soil, where the amount of oxygen is limited, rice roots must compete with microorganisms for the available oxygen. Although aerobic microorganisms partially consume free oxygen in a flooded field, anaerobic microorganisms predominantly consume free oxygen in the flooded mud soil as well as the oxygen contained in other substances such as nitrates, Fe- and Mn-compounds, and sulfates (Takai 1961a, 1961b, 1961c, and 1961d). Deoxidization of sulfates results in the production of detrimental $\mathrm{H}_{2} \mathrm{~S}$ gas, followed by a low activity of $\mathrm{Fe}^{++}$ions due to the formation and deposition of FeS. In order to compensate for the severe oxygen deficiency in direct seeding, pregerminated rice seeds are coated with calcium peroxide $\left(\mathrm{CaO}_{2}\right)$ powder (e.g., Hagiwara et al. 1990). These cultivation techniques have, to some extent, improved seedling establishment in direct seeding (Mitsuishi and Imura 1982). However, how well seedlings are established varies with the cultivation area, the year, the quality of the soil under flooded conditions, and the cultivar (Fujioka 1987). Thus, a better understanding of the genetic characteristics of different rice cultivars may help to develop improved and less expensive methods for establishing seedlings in submerged cultivation areas. However, little information is available on genetic traits that are related to germination and seedling establishment in direct seeding, that is, under de-oxidized conditions. To better understand these traits, we examined varietal variations in rice seedling growth under low oxygen stress with reference to the genealogical relationships of Japanese rice cultivars.

\section{Materials and Methods}

\section{Cultivars}

Twelve rice cultivars that were released between 1882 and 1969 (Table 1 and Fig. 1, data from Kushibuchi 1997) were selected to examine varietal variations in growth characteristics of seedlings in low redox potential culture solution. The seeds were harvested in 1998 and were used for the 
Table 1. Rice cultivars used and their registration year with some remarks

\begin{tabular}{|c|c|c|c|}
\hline \multicolumn{2}{|c|}{ Cultivar } & \multirow{2}{*}{$\begin{array}{c}\text { Registration } \\
\text { year }\end{array}$} & \multirow{2}{*}{ Remarks } \\
\hline Number & Name & & \\
\hline 1 & Aikoku & 1882 & \multirow{4}{*}{$\begin{array}{l}\text { Cultivated during } \\
\text { Meiji and Taisho }\end{array}$} \\
\hline 2 & Kameno-o & 1893 & \\
\hline 3 & Asahi & 1908 & \\
\hline 4 & Riku-u 132 & 1922 & \\
\hline 5 & Norin 8 & 1937 & \multirow{3}{*}{$\begin{array}{l}\text { Cultivated during } \\
\text { the second } \\
\text { world war }\end{array}$} \\
\hline 6 & Norin 1 & 1931 & \\
\hline 7 & Norin 22 & 1943 & \\
\hline 8 & Fujisaka 5 & 1949 & \multirow{5}{*}{$\begin{array}{l}\text { Cultivated after } \\
\text { the second } \\
\text { world war }\end{array}$} \\
\hline 9 & Koshihikari & 1956 & \\
\hline 10 & Sasanishiki & 1963 & \\
\hline 11 & Todoroki-wase & 1968 & \\
\hline 12 & Toyonishiki & 1969 & \\
\hline
\end{tabular}

present experiments after breaking dormancy in 2000 .

\section{Low redox potential solution}

The low redox potential solution was prepared by bubbling with nitrogen gas that had been passed through a $0.5 \%$ $(\mathrm{w} / \mathrm{V})$ pyrogallol solution to eliminate residual oxygen. The redox potential which was maintained in a range of $\mathrm{Eh}=$ -150 to $-180 \mathrm{mv}$ was measured with an Eh gauge (HitachiHoriba Co. Ltd, Kyoto). Furthermore, because hydrogen sulfide $\left(\mathrm{H}_{2} \mathrm{~S}\right)$ gas is naturally present in rice paddy field, the low redox potential solution was bubbled with the $\mathrm{H}_{2} \mathrm{~S}$ gas for 5 minutes at a rate of $2 \mathrm{ml} / \mathrm{min}$. The $\mathrm{H}_{2} \mathrm{~S}$ gas was produced by heating solid hydrogen sulfide (Iimura and Sasahara 2000).

\section{Experiment}

Exactly the same as this text, de-husked seeds were sterilized in $20 \%$ hypochlorite solution for $20 \mathrm{~min}$, washed three times with tap water, and incubated for 2 days at $30^{\circ} \mathrm{C}$ (pre-germination). Then, whole seedlings were immersed in low redox culture solution for 2 days (reduction treatment), and then incubated in 10-cm-deep Petri dishes containing $3 \mathrm{~cm}$ of distilled water for 3 days (recovery period). As a control, seedlings were treated in the same way except that distilled water was used in place of the low redox culture solution. These experiments were conducted in two incubators maintained at 18 and $30^{\circ} \mathrm{C}$.

For each cultivar, three seeds were placed in a stainless wire mesh container $(3 \times 3 \times 3 \mathrm{~cm})$ for pre-germination. Three replications were done for each cultivar. The lengths of shoots and roots were measured.

\section{Evaluation of tolerance and recovery}

The reduction tolerance rates and recovery rates of shoots and roots at 18 and $30^{\circ} \mathrm{C}$ were calculated as follows.

Reduction tolerance rate of shoots $=\frac{\text { Shoot length after reduction treatment }}{\text { Shoot }}$ Shoot length in controls

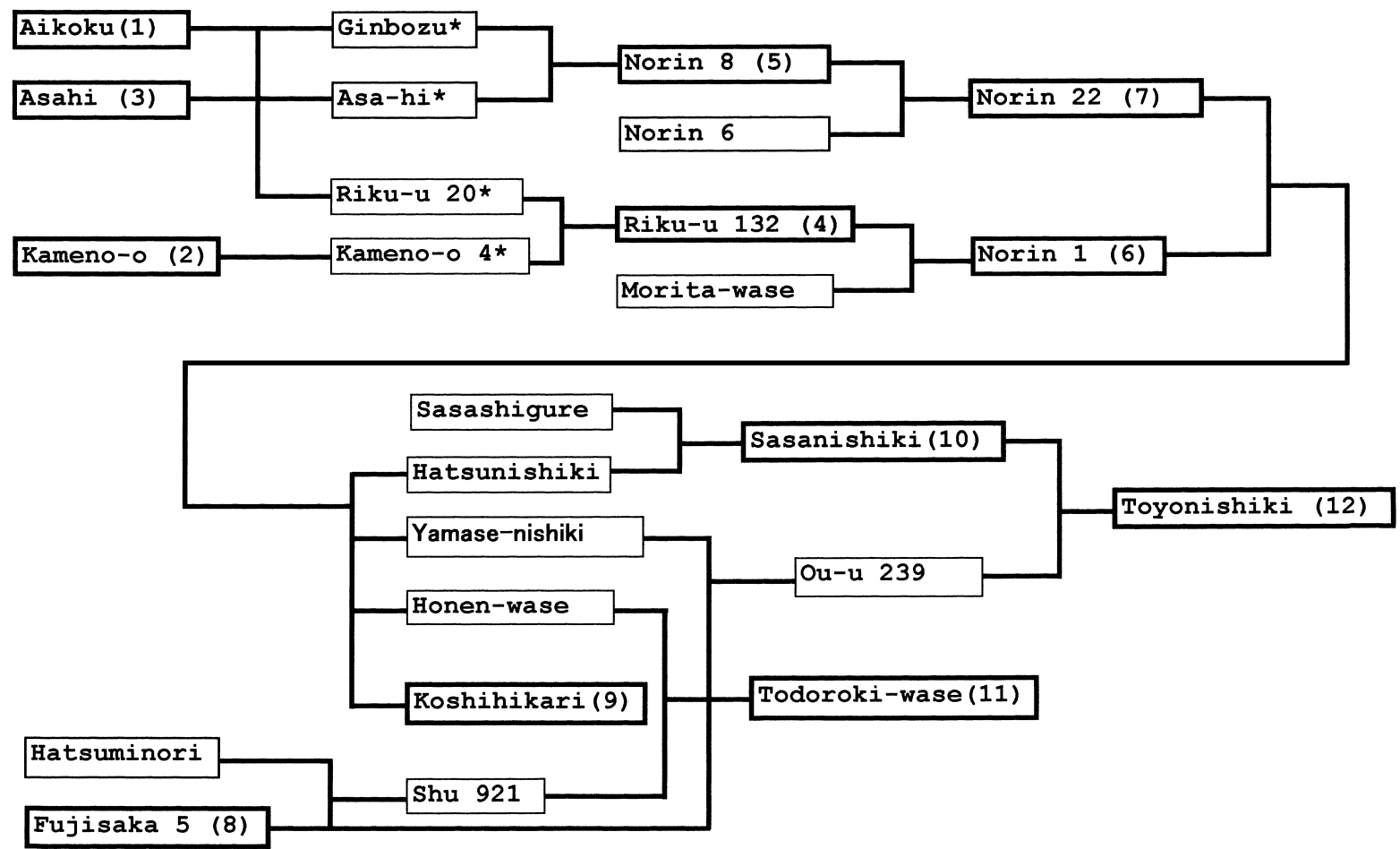

*: Cultivars bred by pure line selection.

The cultivars used in this study are identified by bold rectangles.

Fig. 1. Genealogical relationships of rice cultivars used in this study. 
Reduction tolerance rate of roots $=\frac{\text { Root length after reduction treatment }}{\text { Root length in controls }}$

Recovery rate of shoots $=\frac{\text { Shoot length after recovery period }}{\text { Shoot length in controls }}$

Recovery rate of roots

$$
=\frac{\text { Root length after recovery period }}{\text { Root length in controls }}
$$

\section{Results and Discussion}

Seedlings of the 12 cultivars were immerged in low redox culture solution containing $\mathrm{H}_{2} \mathrm{~S}$ gas for 2 days (reduction treatment), and then incubated in distilled water for 3 days (recovery period), at both 18 and $30^{\circ} \mathrm{C}$. The lengths of shoots and roots of the doubly stressed seedlings are shown in Table 2 and Table 3 , respectively.

At both temperatures, shoot lengths of Fujisaka 5 (No. 8), Sasanishiki, Todoroki-wase and Toyonishiki tended to be longer than those of other cultivars after the reduction treatment. The shoot lengths of Todoroki-wase and Toyonishiki tended to be also longer than those of other cultivars after the recovery period, although three native cultivars, namely, Aikoku, Kameno-o and Asahi, exhibited much higher rates of shoot growth (Table 2). At both temperatures, Riku-u 132, Norin 8, Koshihikari and Toyonishiki exhibited higher rates of root growth than the other cultivars after both the reduction treatment and recovery period (Table 3 ).

These results indicate that shoot growth and root growth are not regulated by simple genetic systems. However, only one cultivar, Toyonishiki showed similar and relatively higher growth rates of shoots and roots under reduction stresses and deliverance from stresses, indicating that genes relating to the growth of shoots and roots under severe stresses or during recovery in the present experiments can be accumulated in one cultivar.

The ratios of shoot or root lengths under reduction and recovery treatments to the corresponding lengths under the control treatments were used to determine the relationships between the reduction tolerance rate and the recovery rate (Fig. 2). At $18^{\circ} \mathrm{C}$, the reduction tolerance rate was not significantly correlated with the recovery rate in either shoots or roots. Values of these two parameters ranged from 60 to $130 \%$ in shoots and from 40 to $100 \%$ in roots, i.e., they varied over relatively narrow ranges. These results indicate that the reduction treatment under the added stress of low temperature, i.e., under double stress, severely depressed seedling growth of all the cultivars used. However, the recovery rates of shoots and roots tended to be slightly higher in Aikoku and Kameno-o, indicating that the air-ventilation system in these cultivars described by Arikado (1955) had developed rapidly compared with other cultivars. Thus, these cultivars appear to be a genetic resource that can be used to improve the leading cultivars, which are not adapted for direct seeding.

At $30^{\circ} \mathrm{C}$, the reduction tolerance rate was positively and significantly correlated with the recovery rate in both shoots and roots. The reduction tolerance rate and the recovery rate in both shoots and roots were higher in Norin 22, as they were in Kameno-o, Fujisaka 5, Todoroki-wase, and Toyonishiki. However, they were lower in the descendants of Norin 22, such as Sasanishiki and Koshihikari, than in other cultivars. Therefore, the higher reduction tolerance and recovery rates in Todoroki-wase and Toyonishiki seem to

Table 2. Shoot lengths of rice seedlings

$(\mathrm{mm})$

\begin{tabular}{|c|c|c|c|c|c|c|c|c|c|}
\hline \multirow{3}{*}{ Cultivars } & \multirow{3}{*}{$\begin{array}{c}30^{\circ} \mathrm{C} \\
\text { After pre- } \\
\text { incubation }\end{array}$} & \multicolumn{4}{|c|}{$18^{\circ} \mathrm{C}$} & \multicolumn{4}{|c|}{$30^{\circ} \mathrm{C}$} \\
\hline & & \multicolumn{2}{|c|}{$\begin{array}{l}\text { After 2-day } \\
\text { treatment }\end{array}$} & \multicolumn{2}{|c|}{$\begin{array}{l}\text { After 3-day } \\
\text { recovery period }\end{array}$} & \multicolumn{2}{|c|}{$\begin{array}{c}\text { After 2-day } \\
\text { treatment }\end{array}$} & \multicolumn{2}{|c|}{$\begin{array}{c}\text { After 3-day } \\
\text { recovery period }\end{array}$} \\
\hline & & $\mathrm{DW}^{1)}$ & $\mathrm{LRS}^{2)}$ & DW & LRS & DW & LRS & DW & LRS \\
\hline 1. Aikoku & 1.44 & 2.47 & 1.69 & 4.12 & 4.04 & 4.25 & 2.41 & 5.27 & 4.28 \\
\hline 2. Kameno-o & 1.89 & 2.13 & 1.71 & 2.77 & 3.56 & 2.78 & 2.36 & 4.66 & 4.29 \\
\hline 3. Asahi & 1.24 & 1.69 & 1.72 & 3.51 & 3.18 & 3.76 & 1.72 & 4.92 & 4.71 \\
\hline 4. Riku-u 132 & 1.16 & 1.61 & 1.42 & 3.29 & 2.75 & 4.25 & 1.53 & 6.48 & 2.72 \\
\hline 5. Norin 8 & 1.29 & 1.91 & 1.64 & 3.36 & 2.46 & 3.56 & 1.67 & 4.94 & 3.55 \\
\hline 6. Norin 1 & 0.79 & 2.21 & 1.77 & 3.11 & 2.52 & 3.28 & 2.09 & 3.71 & 2.01 \\
\hline 7. Norin 22 & 0.84 & 1.71 & 1.55 & 1.93 & 1.71 & 2.36 & 1.55 & 2.66 & 2.19 \\
\hline 8. Fujuisaka 5 & 0.69 & 2.03 & 1.83 & 2.75 & 2.16 & 3.11 & 2.04 & 3.86 & 3.16 \\
\hline 9. Koshihikari & 0.77 & 1.79 & 1.47 & 2.99 & 2.15 & 3.19 & 1.53 & 6.02 & 2.54 \\
\hline 10. Sasanishiki & 1.11 & 1.81 & 1.92 & 2.85 & 2.25 & 3.21 & 2.45 & 4.68 & 2.86 \\
\hline 11. Todoroki-wase & 1.23 & 3.91 & 2.91 & 4.19 & 3.28 & 3.65 & 3.75 & 4.31 & 4.44 \\
\hline 12. Toyonishiki & 1.12 & 2.36 & 2.15 & 3.02 & 2.81 & 3.41 & 2.69 & 3.58 & 3.25 \\
\hline $\mathrm{LSD}^{3)}$ & 0.07 & 0.10 & 0.09 & 0.14 & 0.12 & 0.13 & 0.16 & 0.31 & 0.16 \\
\hline
\end{tabular}


Table 3. Root lengths of rice seedlings

$(\mathrm{mm})$

\begin{tabular}{|c|c|c|c|c|c|c|c|c|c|}
\hline \multirow{3}{*}{ Cultivars } & \multirow{3}{*}{ 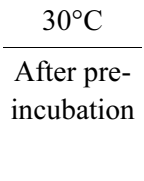 } & \multicolumn{4}{|c|}{$18^{\circ} \mathrm{C}$} & \multicolumn{4}{|c|}{$30^{\circ} \mathrm{C}$} \\
\hline & & \multicolumn{2}{|c|}{$\begin{array}{l}\text { After 2-day } \\
\text { treatment }\end{array}$} & \multicolumn{2}{|c|}{$\begin{array}{l}\text { After 3-day } \\
\text { recovery period }\end{array}$} & \multicolumn{2}{|c|}{$\begin{array}{l}\text { After 2-day } \\
\text { treatment }\end{array}$} & \multicolumn{2}{|c|}{$\begin{array}{c}\text { After 3-day } \\
\text { recovery period }\end{array}$} \\
\hline & & $\mathrm{DW}^{1)}$ & LRS $^{2)}$ & DW & LRS & DW & LRS & DW & LRS \\
\hline 1.Aikoku & 0.73 & 1.39 & 0.76 & 1.28 & 1.36 & 1.34 & 0.76 & 1.85 & 0.92 \\
\hline 2.Kameno-o & 0.53 & 0.68 & 0.58 & 0.89 & 0.81 & 0.73 & 0.68 & 1.08 & 0.67 \\
\hline 3.Asahi & 0.63 & 1.51 & 0.82 & 3.31 & 2.26 & 4.11 & 0.82 & 5.95 & 1.98 \\
\hline 4.Riku-u 132 & 1.46 & 2.32 & 1.71 & 2.75 & 4.89 & 4.27 & 1.48 & 3.82 & 1.96 \\
\hline 5.Norin 8 & 2.31 & 3.74 & 2.29 & 4.07 & 2.65 & 4.25 & 2.34 & 4.61 & 2.52 \\
\hline 6.Norin 1 & 0.91 & 1.53 & 1.31 & 2.01 & 1.49 & 2.01 & 1.41 & 2.11 & 1.53 \\
\hline 7.Norin 22 & 0.77 & 1.97 & 1.03 & 1.83 & 1.26 & 1.19 & 1.18 & 1.61 & 1.26 \\
\hline 8.Fujuisaka 5 & 1.05 & 1.78 & 1.55 & 1.83 & 1.61 & 2.01 & 1.55 & 2.28 & 2.19 \\
\hline 9.Koshihikari & 1.72 & 3.08 & 1.91 & 3.49 & 2.31 & 2.99 & 1.46 & 3.51 & 1.62 \\
\hline 10.Sasanishiki & 0.33 & 1.09 & 0.51 & 2.55 & 1.13 & 2.49 & 0.42 & 4.59 & 1.46 \\
\hline 11.Todoroki-wase & 1.45 & 1.76 & 1.52 & 2.12 & 1.67 & 1.71 & 1.64 & 2.16 & 1.73 \\
\hline 12. Toyonishiki & 1.77 & 2.17 & 2.06 & 3.14 & 2.28 & 2.11 & 1.91 & 2.48 & 2.28 \\
\hline $\mathrm{LSD}^{3)}$ & 0.11 & 0.13 & 0.12 & 0.10 & 0.21 & 0.12 & 0.16 & 0.14 & 0.19 \\
\hline
\end{tabular}

1) DW: seeds were incubated in distilled water.

2) LRS: seeds were incubated in low redox solutions.

3) LSD: least square difference at the 0.05 probability level.

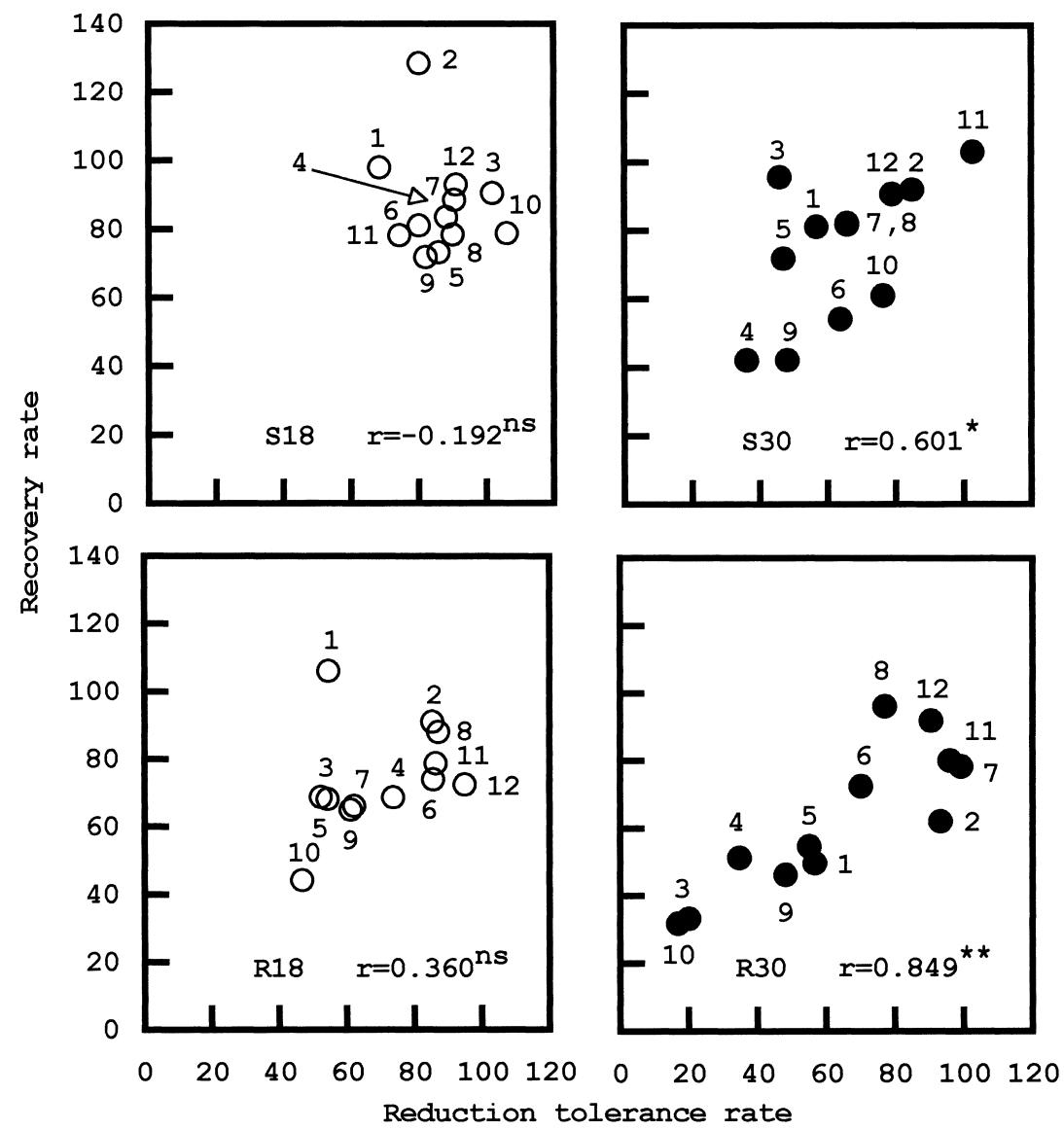

Fig. 2. Relationships between reduction tolerance rate and recovery rate for shoots at $18^{\circ} \mathrm{C}(\mathrm{S} 18)$ and $30^{\circ} \mathrm{C}(\mathrm{S} 30)$ and for roots at $18^{\circ} \mathrm{C}(\mathrm{R} 18)$ and $30^{\circ} \mathrm{C}(\mathrm{R} 30)$. Ordinate: Percent length of control after 3-day recovery period. Abscissa: Percent length of control after reduction treatment for 2 days. Numbers in Figure show cultivars.

1. Aikoku, 2. Kameno-o, 3. Asahi, 4. Riku-u132, 5. Norin 8, 6. Norin 1, 7. Norin 22, 8. Fujisaka 5, 9. Koshihikari, 10. Sasanishiki, 11. Todoroki-wase, 12. Toyonishiki. 
have originated from Fujisaka 5, rather than from the ancient and famous ancestors of the recent cultivars with higher eating quality, Kameno-o and Norin 22 (Fig. 1 and Fig. 2).

About 550,000 ha, corresponding to about $35 \%$ of the area used for rice cultivation in Japan, are devoted to Koshihikari, almost all of which is transplanted. Direct seeding cultivation of Koshihikari would save labor and cultivation costs, but unfortunately Koshihikari is not suitable for direct seeding (Hagiwara and Imura 1993). Although the present results are consistent with this assessment, the genetic traits related to the reduction tolerance rate and the recovery rate of Koshihikari can be improved by crossing it with Todoroki-wase and Toyonishiki as well as by crossing it with Kameno-o, Norin 22 and Fujisaka 5.

\section{Literature Cited}

Arikado,H. (1955) Studies on development of the ventilating system in relation to the tolerance against excess-moisture injury in various crop plants. The ventilating pressure in the rice plants grown in paddy-field condition. Proc. Crop Sci. Soc. Jpn. 23: 285-286 (in Japanese with English summary).

Fujioka,S. (1987) Development of new paddy growing technology practices on the shallow seeding in the submerged paddy field and in-line drill fertilizing. Farming Mech. 2830: 4-13 (in Japanese).

Hagiwara,M. and M.Imura (1993) Varietal difference and temperature response of local soil-reduction around germinating rice seed. Jpn. J. Crop Sci. 62: 105-110 (in Japanese with English summary).

Hagiwara,M., M.Imura and S.Mitsuishi (1990) Local soil reduction in the vicinity of the paddy rice seed coated with oxygen generating chemicals in relation to germination and emergence. Jpn. J.
Crop Sci. 59: 56-62 (in Japanese with English summary).

Iimura, K. and T.Sasahara (2000) Preparation of de-oxidized and low oxidation-reduction solution - An attempt to examine response characteristics of rice seedlings to reduction. Root Res. 9: 65-67 (in Japanese).

Kanda,M. and N.Takahashi (1951) Studies on the germination of rice seed. Part I. The speed of germination and the appearance of plumule and radicle. Bull. Inst. Agric. Res. Tohoku Univ. 3: 155-170 (in Japanese with English summary).

Kawai,N. and H.Uchimiya (1999) Molecular characteristics of aerenchyma formation and cell death in rice plant. Root Res. 8: 125127 (in Japanese).

Kushibuchi,K. (1997) Historical changes in rice cultivars. In "Science of the rice plant. Genetics (Vol. 3)" Matsuo, T. (ed.), Nobunkyo, Tokyo. p. 837-875.

Mitsuishi,S. and M.Imura (1982) A study of direct sowing of paddy rice (1). Agr. Hort. 57: 1265-1268 (in Japanese).

Miura,S. (1933) Effect of the air in the culture media upon the growth of roots in rice plant. Proc. Crop Sci. Soc. Jpn. 5: 422-430 (in Japanese).

Takahashi,N. (1955) Studies on the varietal differences to the velocity of germination of rice seeds. Bull. Inst. Agric. Res. Tohoku Univ. 7: 1-12.

Takai,Y. (1961a) Reduction of paddy soil in relation to activities of micro-organisms (1). J. Agr. Sci. (Tokyo) 16: 1-4 (in Japanese).

Takai,Y. (1961b) Reduction of paddy soil in relation to activities of micro-organisms (2). J. Agr. Sci. (Tokyo) 16: 51-53 (in Japanese).

Takai,Y. (1961c) Reduction of paddy soil in relation to activities of micro-organisms (3). J. Agr. Sci. (Tokyo) 16: 122-126 (in Japanese).

Takai,Y. (1961d) Reduction of paddy soil in relation to activities of micro-organisms (4). J. Agr. Sci. (Tokyo) 16: 162-166 (in Japanese). 